\title{
COMPARISON OF BIOCHEMICAL MICROBIAL EFFECTS IN ENHANCED OIL RECOVERY (MEOR)
}

\author{
E. T. Premuzic, M. S. Lin, and B, Manowitz*
}

\author{
Department of Applied Science \\ Biosystems and Process Sciences Division \\ * Physical Sciences Division \\ Brookhaven National Laboratory \\ Upton, NY 11973
}

November 1992

\author{
To be Presented at the \\ American Chemical Society \\ Denver, CO \\ March 28 - April 2, 1993
}

DISCLAIMER

\begin{abstract}
This report was prepared as an account of work sponsored by an agency of the United States Government. Neither the United States Government nor any agency thereof, nor any of their employees, makes any warranty, express or implied, or assumes any legal liability or responsibility for the accuracy, completeness, or usefulness of any information, apparatus, product, or process disclosed, or represents that its use would not infringe privately owned rights. Reference herein to any specific commercial product, process, or service by trade name, trademark, manufacturer, or otherwise does not necessarily constitute or imply its endorsement, recommendation, or favoring by the United States Government or any agency thereof. The views and opinions of authors expressed herein do not necessarily state or reflect those of the United States Government or any agency thereof.
\end{abstract}


COXPARISON OF BIOCHEMIGAI MICROBIAL EFFECTS IN

ENHANCED OIL RECOVERY (MEOR)

Eugene T. Premuzic, Mow S. Lin, and *Bernard Manowitz

Department of Applied Science

Biosystems and Process Sciences Division

*Applied Physical Sclences Division

Brookhaven National Laboratory

Upton, NY 11973

\section{Extended Abstract}

Experimental data dealing with the interactions between certain microbial species and crude oils indicates that these interactions are selective and occur via biochenical pathways which can be characterized by the chemical composition of the initial crude 011 and that of the end products. In the studies to be discussed in this paper, the microblal species used were thermophilic and/or thermoadapted microorganisms which thrive in harsh environments (e.g., pH, temperature, pressure, salinity). Crude oils chosen for blotreatment represented a wide range of oils, which varied from relatively light oils to heavy, high sulfur content olls. The crude olls used have also been distinguished in terms of their geological history, 1.e., heavy, because they are immature or heavy, because they have been biodegraded. The significance of "biodegraded" vs. "biotreated" crude oil in MEOR will also be discussed.

1. Microbial Enhanced Oil Recovery (MEOR) is an emerging biotechnology which now claims several successes in this country and abroad. These have been reviewed and discussed by (Mcses 1991; Bryant 1991) and most recently at the International Conference on MEOR (Premuzic and Woodward 1992). Successful microbial candidates are capable of growth under reservoir condition which include high salinities, some up to $75,000 \mathrm{ppm}$, temperatures $\left(-80^{\circ} \mathrm{C}\right)$ and pressures $-1500 \mathrm{psi}$ ). As a consequence of their metabolic activity they produce gases, acids, surface active polymers and reduce viscosity of crude oils.

2. Studies in this laboratory have shown (Premuzic and Lin 1990, 1991, 1992) that the interactions between microorganisms and crude oils are selective and occur via biochemical pathways which can be characterized by the chemical composition of the crude oil and that of the end products. "Biomarkers", 1.e., chemical signals wich describe chemical changes in the crude oil due to maturation, blodegradation, migration, and others have been used extensively in oil exploration and characterization (Peters and Moldowan 1992). The data discussed in this paper differentiate between the terms "biodegradation" and "blotreatment." The latter means biochemical conversion of crude oils due to introduced microorganisms and the former means changes which have occurred in the reservoir over geological perlods of time. Introduction of nutrients in to a reservolr may also be considered as 
blotreatment, because it does stimulate, the growth of indigenous alcroorganisms, however, over a much shorter perfod of time (relative to geological scale, 1.e., months vs. millions of years). Under the experimental conditions used, blotreatment of crude olls with thermophilic and thermoadapted microorganisms affects a number of parameters which are 11sted in Table 1. A brief discussion in terms of some typical examples follows.

Table 1. Blochemical Effects on Crude Olls Due to Microbial Treatment

- Variation in the extent of emulsion.

- Presence or absence of an added surface active agent.

- Duration of treatment.

- Changes in chemical markers: hydrocarbons.

- Changes in chemical markers: organtc sulfur compounds.

- Changes in chemical markers: organometallic compounds.

- Action on different types of heavy crude olls, 1.e., heavy, because they are immature or heavy because they are blodegraded.

- Introduced microorganisms appear to become dominant.

- The effects due to biotreatment are not random, but follow distinct treads which are both microbial species and chemical compositions of crude oils dependent.

Biotreatment with several microorganisms of heavy fraction of different crude oils, leads to emulsification of the crudes. The results shown in Table 2, indicute that the extent of emulsification varies with microbial species used and the type of o1l treated. In all the cases, the oil was the sole source of carbon.

Table 2. Extent of Emulsification Due to the Action of Various Microorganisms on Heavy Fraction of Crude Oils. The Results are Expressed in Klett Units (Roseberg 1979).

$\begin{array}{lcccc}\text { Asphalt } & \begin{array}{c}\text { Wilmington } \\ \text { (California) }\end{array} & \begin{array}{c}\text { Goch Saran } \\ \text { (Iran) }\end{array} & \begin{array}{c}\text { Recluse } \\ \text { (Wyoming) }\end{array} & \begin{array}{c}\text { Prudhoe } \\ \text { (Alaska) }\end{array}\end{array}$

\begin{tabular}{lrllll}
\hline BNL-4-24 & 35 & 115 & 168 & 250 & 215 \\
BNL $-4-23$ & 250 & 290 & 238 & 225 & 195 \\
BNL-4-22 & 275 & 252 & 320 & 175 & 285 \\
BNL-4-21 & 475 & 515 & 142 & 600 & 615 \\
\hline
\end{tabular}

Similar effects are observed in an identical treatment of Venezuelan Boscan crude, a heavy immature crude, and Cerro Negro a heavy biodegraded crude oil. The results of biotreatment of these oils with several microorganisms are represented graphically in Figure la,b for two Media (Premuzic and Lin 1991, Premuzic et al. 1992). Media 1 contains inorganic salts only with ofl as the sole carbon source, while Media 2 contains inorganic salts, a small amount of added organic nutrient $(<0.0088)$ and crude oll. In some cases, a 


\section{BIOTREATMENT OF BOSCAN CRUDE}

40 DAYS MIEDIA 1 vS MEDIA 2

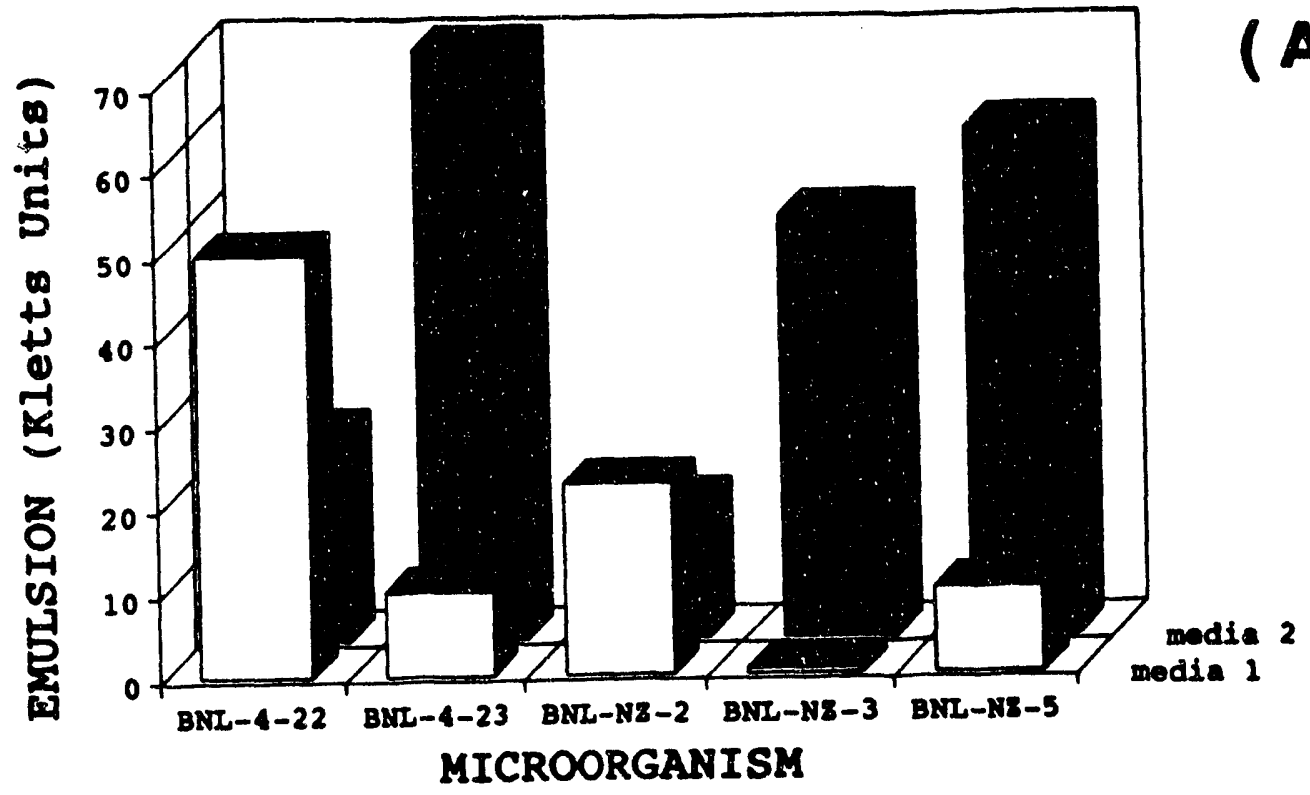

BIOTREATMENT OF CERRO NEGRO CRUDE

40 DAYS MEDIA 1 vs MEDIA 2

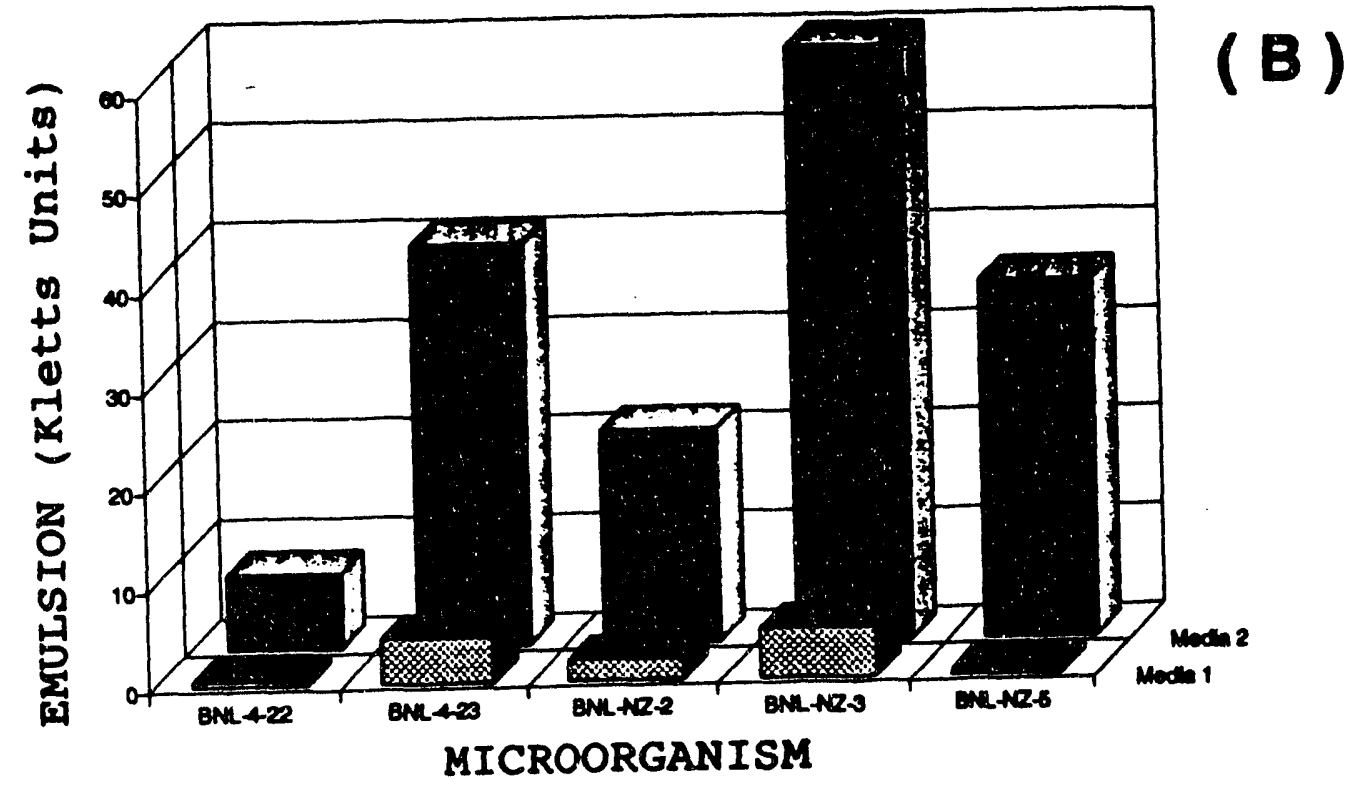

Figure 1 
considerable enhancement as well as shortening in the duration of biotreatment can be achleved by adding a surface active agent to the reaction mixture as shown in Figure 2. Concurrent effects on other biomarkers, specifically distribution of hydrocarbons, conversion of organic sulfur compounds and organonetallic compounds have been reported and discussed in detall (Premuzic and Lin 1990, 1991a,b,c). The results are summarized as follows:

1. There is a decrease in $C_{30}$ fraction of crudes with an increase in the concentration of the lighter $\left(<C_{20}\right)$ fractions.

2. There is a conversion of complex asphaltene fraction rich in organic sulfur compounds to lighter components with a net result of a decrease in the total organic sulfur content.

3. Analyses indicate that the conversion of organic sulfur compounds decreases the sulfide and thiophene contents and increases the sulfoxide contents.

4. During the biotreatment there is an overall removal of trace metals from the organic phase, 1.e., the crude oil phase. At present it is thought that this is due to solubilization of metallic species in the aqueous phase.

Further refinement and optimization of bioprocessing has led to shortening in the time of blotreatment and choice of oll-microorganism combinations. The latter, support the view that the study of trends in the biochemical interactions between crude oils and microorganism selected for MEOR may lead to the development of a data base identifying chemical markers as diagnostic tools in determining MEOR process strategies. Examples of this type of information are given in Figure 3 , in which blotreatment of two crudes is compared: Monterey A837 an immature heavy off-shore crude, and Monterey A851 a heavy on-shore biodegraded California crude oil. Gas ChromatographyMass Spectroscopy (GC-MS) fragmentograms are given for the hydrocarbon distribution before and after the biotreatment. In all cases, the crude olls were the sole source of carbon biotreated over a period of seven days and the absence of an added detergent. These results clearly indicate that BNL-4-23, a thermoadapted microorganism and BNL-NZ-3 a thermophilic, act effectively on A837, however, only BNL-NZ-3 is highly efficient in the bioconversion of the A851 crude. A plausible mechanism by which the biochemical conversion of crudes may occur, would involve initial reactions at the functional sites of the complex polar fractions of the crudes, such as, those present in the asphlaltenes. Monterey A851 is rich in the content of the polar N, S, 0 compounds, therefore, the effect, for example, on the organic sulfur compounds should be significant as shown in Figures 4 and 5 . In routine analyses of organic sulfur components by Gas Chromatography equipped with sulfur specific Flame Photoemission Detector (FPD), the crude oil sample is injected at a relatively low fixed temperature (typically $-350^{\circ} \mathrm{C}$ ). Under these experimental conditions it is the volatilized fraction of the sample that is chromatographed. Thus, if the proposed mechanism involving functional sites is correct, then the untreated control and the sample biotreated with BNL-423, should have 1ittle or no effect on the Monterey A851 crude, a very heavy, non-volatile oil. The resulting FPD chromatogram should show a low response even at high sensitivity settings of the instrument. The results shown in Figure 4 are consistent with this. Chromatograms of both treated and untreated oil were recorded at the same sensitivity (attenuation 32). In both cases identical sample injections were used. Identical experimental conditions were used for the biotreated sample. Control sample at a higher sensitivity (attenuation 16) relative to that in Figure 4 did not even come close to the BNL-NZ-3 blotreated A851. In fact, the sensitivity 


\section{BIOTREATMENT OF BOSCAN CRUDE IN THE PRESENCE OF A DETERGENT}

\section{PLUS DETERGENT 20 vs 40 DAYS}

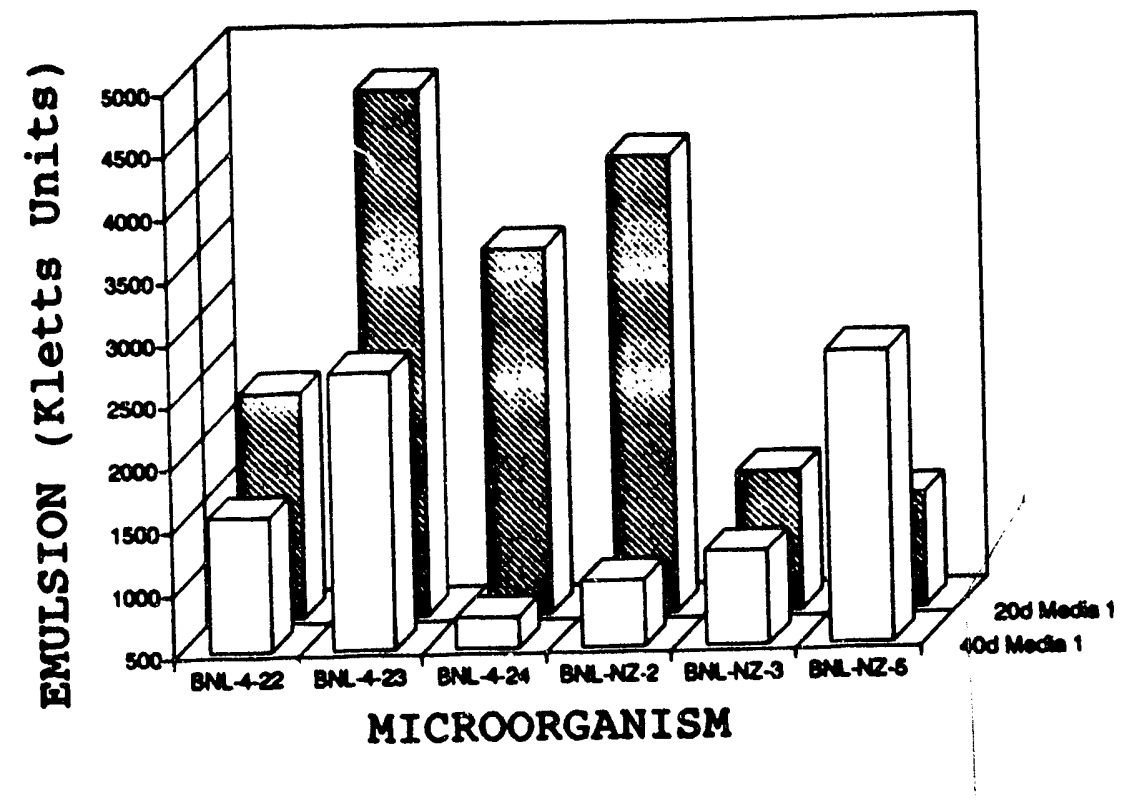



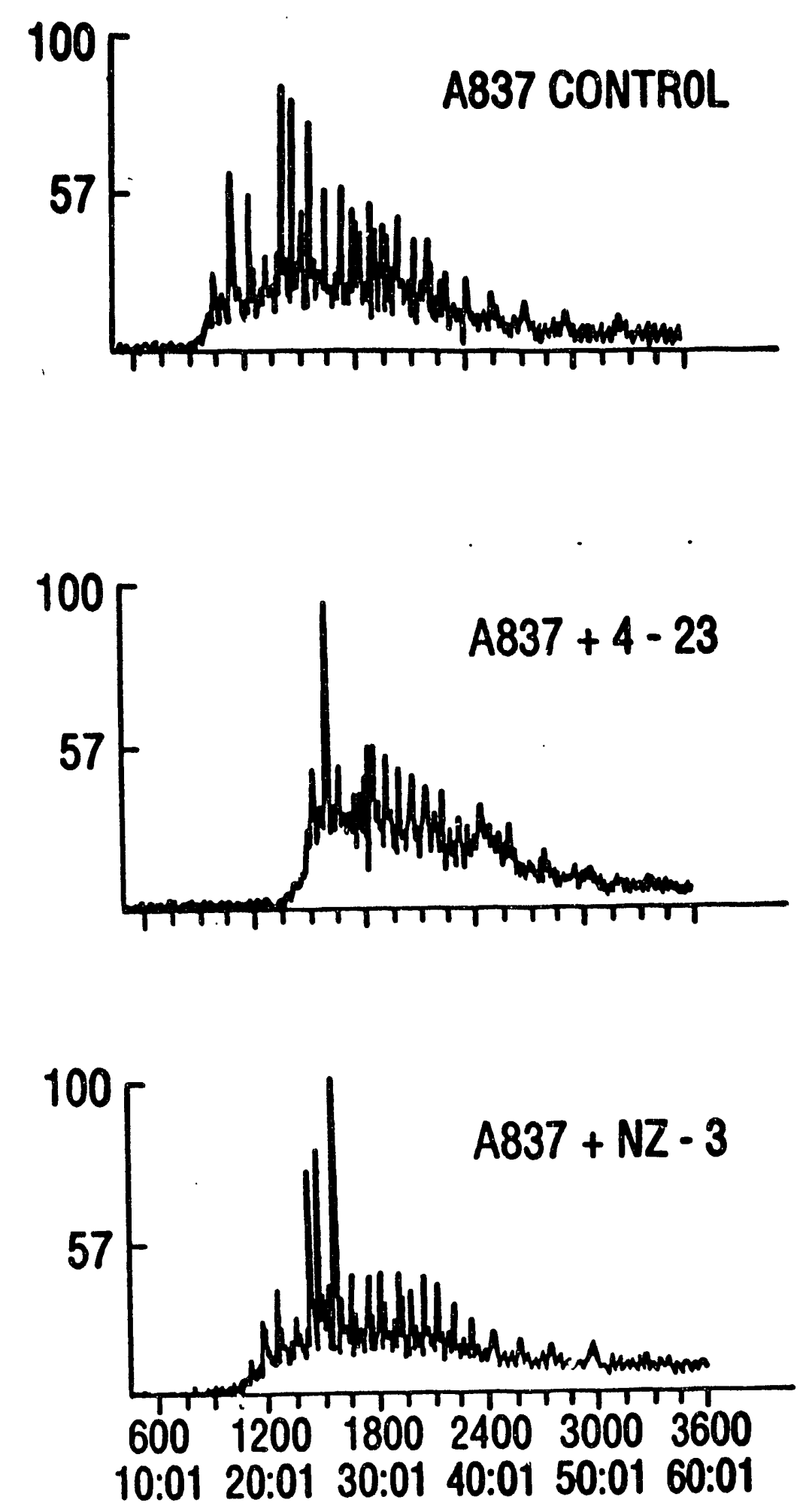

Figure 3a - GC-MS Fragmentograms, M/Z 57, Monterey, CA, Crude A837 Treated with BNL-4-23 and BNL-NZ-3. 

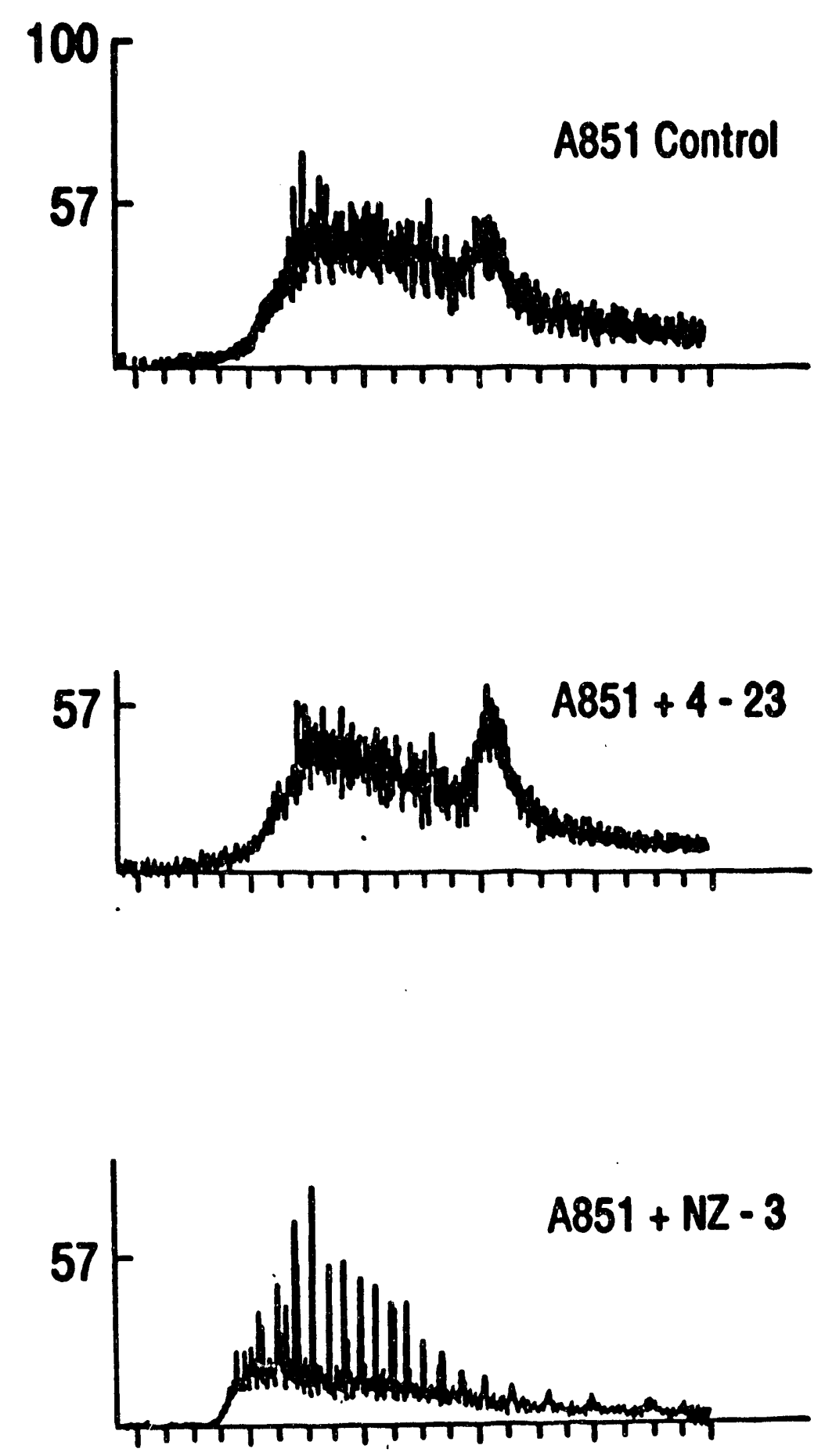

Figure 3b - GC-MS Fragmentograms, m/z 57, Monterey, CA, crude A851 treated with BNL-4-23 and BNL-NZ-3. 

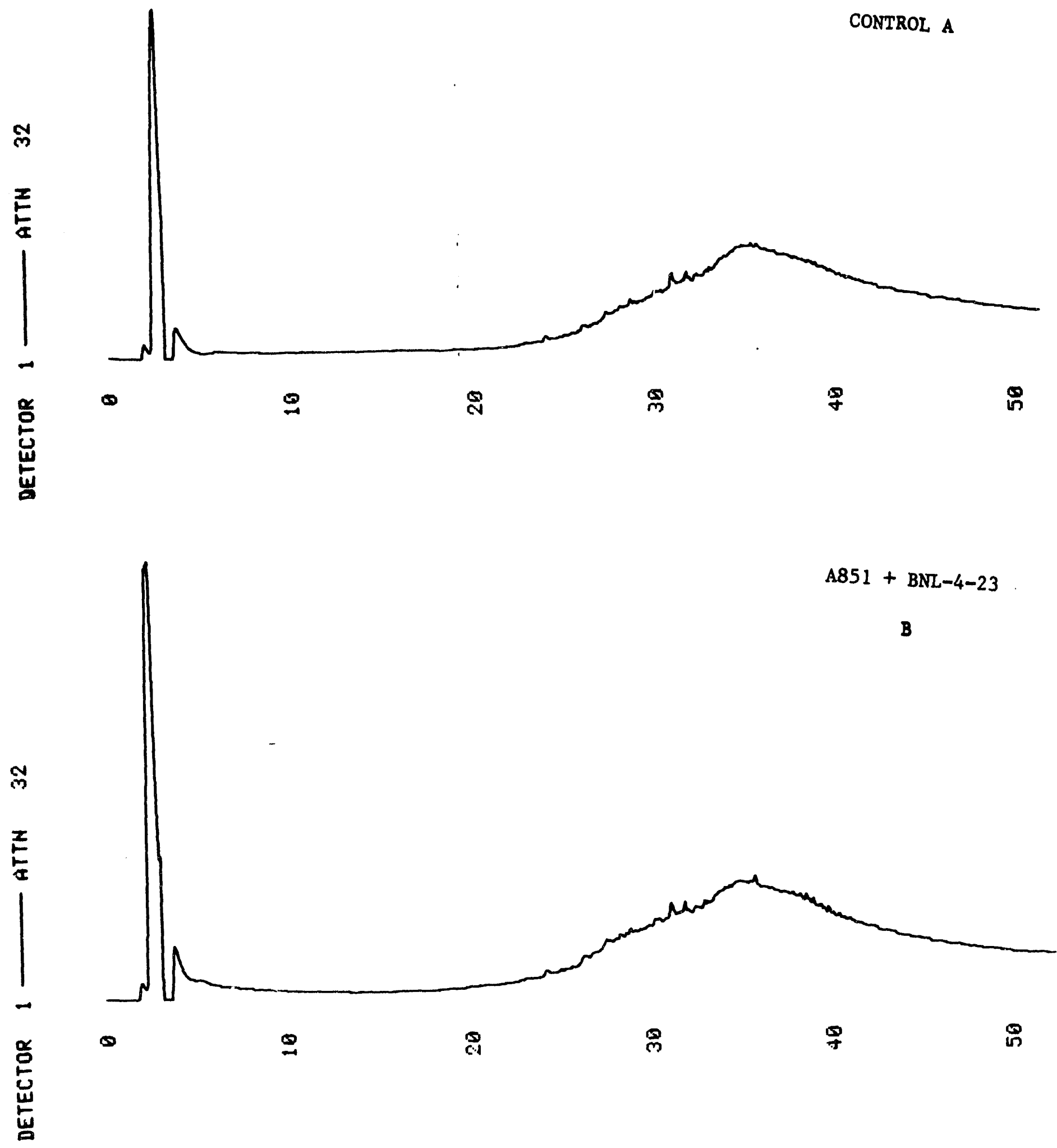

Figure 4 - Monterey, CA, A851 crude, A: Control, media 3, seven days; B: Biotreated with BNL-4-23. 


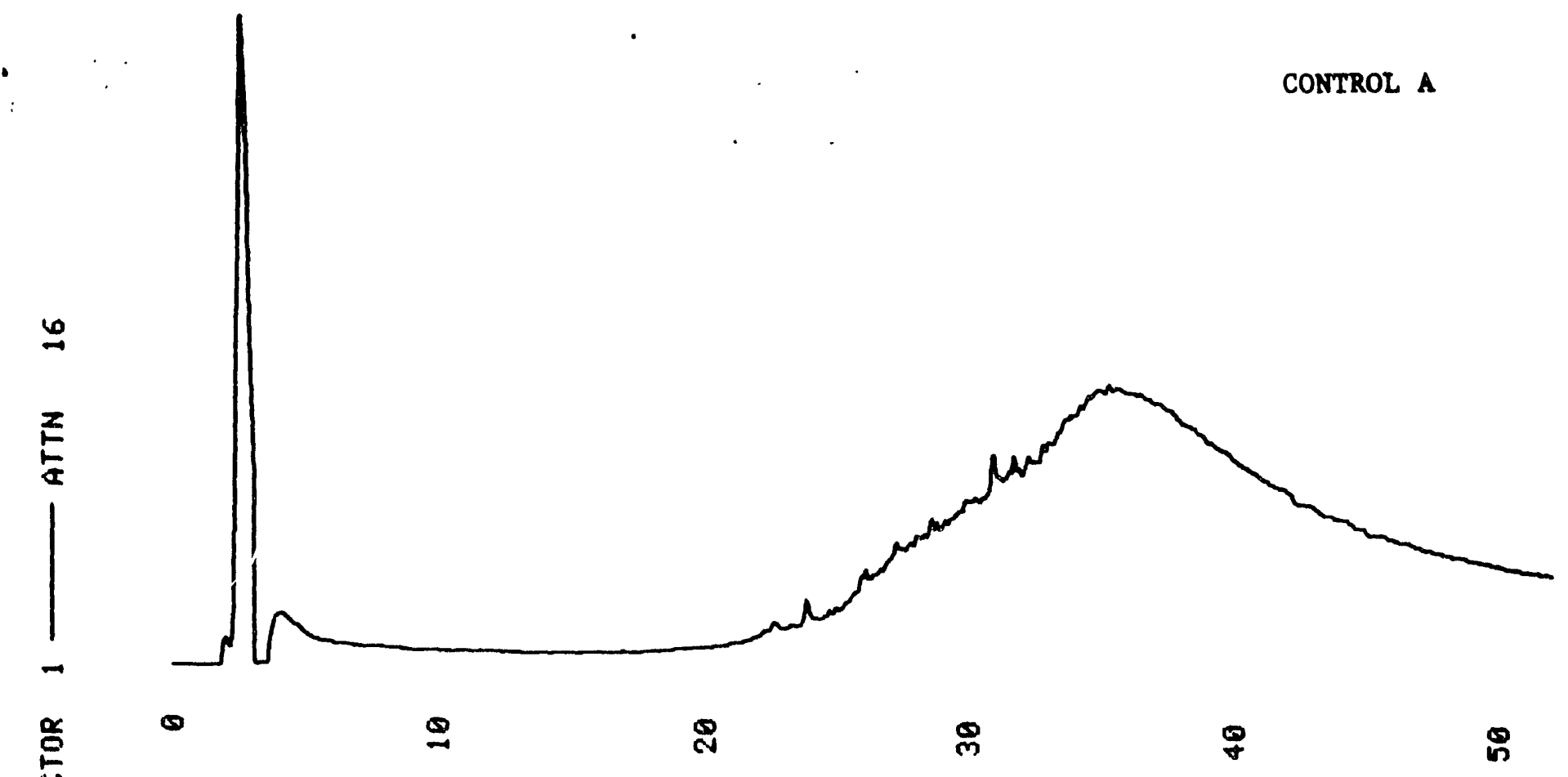

岕

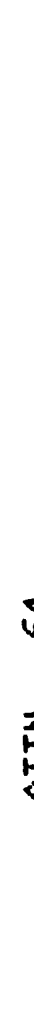

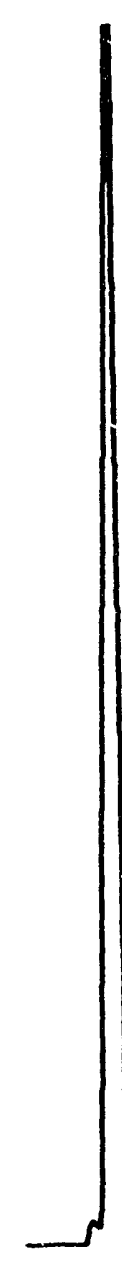

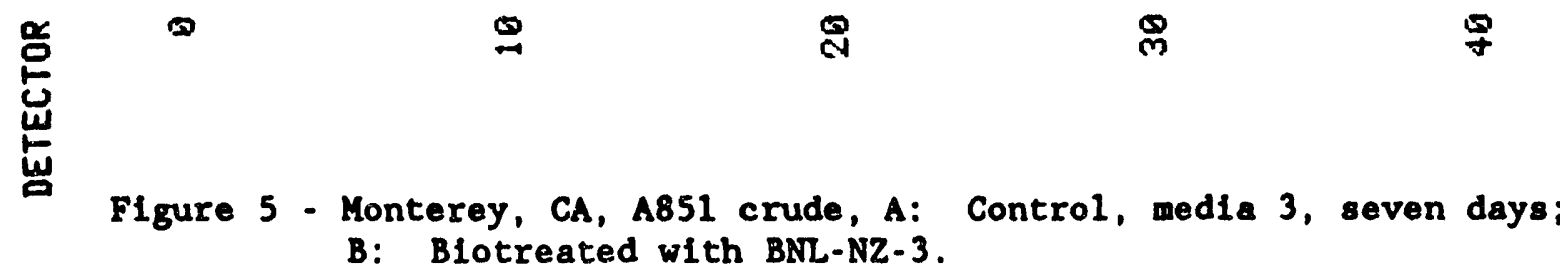

B: Blotreated with BNL-NZ-3. 
(attenuation 64) had to be lowered to get the corresponding signal, indicating that the bioconversion of $A 851$ resulted in generation of a more volatile product. The results of these studies also stress the significance of the terms of "blodegraded" and "blotreated". Both Cerro Negro and Mc.terey A851 are heavy oils because they were blodegraded in reservolrs over geological perlods of time. Therefore, blotreatment as referred to here converts crude oils, including those that were biodegraded into forms more amenable to enhanced recovery. Concurrent desulfurization and demetallization contribute additional downstream quality enhancement of the crude oll.

Since all of the experiments were carried out under identical experimental conditions the differences in the attenuation may be used as an approximation of the bioconversion. Experimental approaches such as described above have been extended to other oils and used as "diagnostic" guide in the choice of the core-flooding experiments to be discussed in concluding remarks of the presentation.

\section{Acknowledgements}

This work is supported by the U.S. Department of Energy, Division of Fossil Fuels through the Bartlesville Field office under Contract No. AS-219-ECD and Contract No. DE-AC02-76CH00016 with the U.S. Department of Energy. We wish to thank W. D. Peters, formerly of the Bartlesville Field Offilce, and $M$. McCaffrey of Chevron, for gifts of oil samples and valuable comments.

\section{References}

V. Moses, "MEOR in the Field: Why so Little?" Microbial Enhanced Oil Recovery - Recent Years, (New York, NY: Elsevier Publishing Company, 1991),

R. S. Bryant, "Microbial Enhanced Oil Recovery: State-of-the-art Review," Research Needs to Maximize Econoline Productivity of the Domestic 011 Resource, (NIPER-527 (DE92001001, 1991).

E. T. Premuzic, Proc. Fourth International Conference on Microbial Enhanced Oil Recovery, eds. E. T. Premuzic and A. Woodward (New York, NY: Elsevier Publishing Company, 1993), in preparation.

E. T. Premuzic, et. al., "Chemical Markers of Induced Microbial Transformation in Crude 0ils," Fourth International Conference on Microbial Enhanced 011 Recovery, eds. E. T. Premuzic and A. Woodward (New York, NY: Elsevier Publishing Company, 1993) in preparation.

E. T. Premuzic and M. S. Lin, "Prospects for Thermophilic Microorganisms in Microbial Enhanced Oil Recovery (MEOR)," International Conference on Microbial Enhancement of 011 Recovery - Recent Advances, ed. E. C. Donaldson, (Norman, OK: Developments in Petroleum Science, 1991) Vol. 31, Chap. R-18, 277-296.

E. T. Premuzic and M. S. Lin, "Interactions Between Thermophilic Microorganisms and Crude 011s: Recent Developments, "Resources. Conservation and Recycling, 5 (1991), 277-284.

E. T. Premuzic and M. S. Lin, "Prospects for Thermophilic Microorganisms in Microbial Enhanced 011 Recovery (MEOR)--Part II," International Symposium on 011 Field Chemistry," (Anaheim, CA: Society of Petroleum Engineers, SPE 21015, 1991) 143-148. 
K. E. Peters and J. M. Moldwan, "Blomarker Gulde," (Prentice Hall, 1992), 363.

E. Rosenberg, et al., "Emulsifier of Arthrobacter RAG-1: Isolation and Emulsifying Properties, "Appl, and Environmental Microbiol 37 (3) (1979), 402 408. 

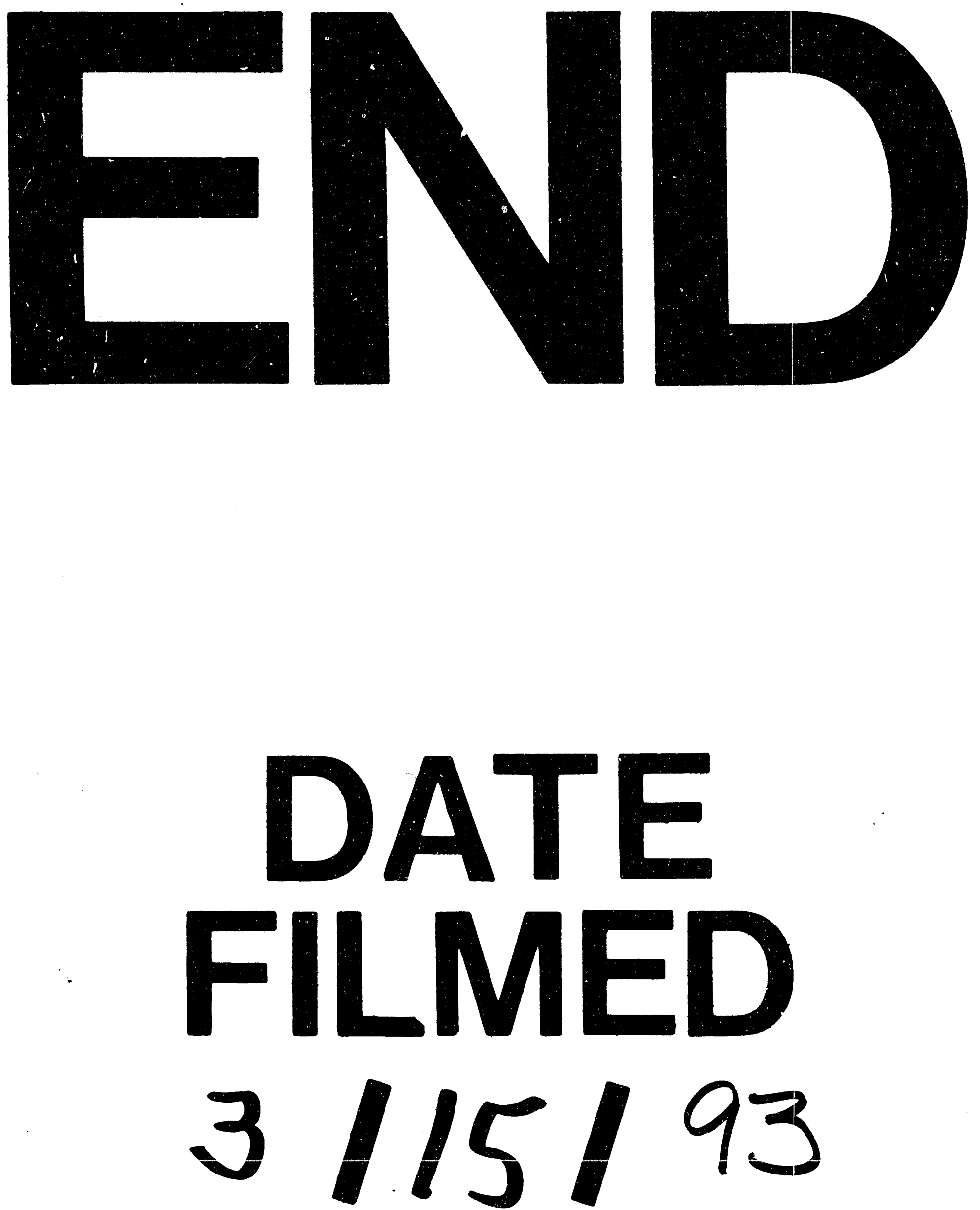
